\title{
Properties of acetylcholine-induced hyperpolarization in smooth muscle cells of the mouse mesenteric artery
}

\author{
Makoto KosHITA ${ }^{1}$, Kiyoshi HidAKA ${ }^{2}$, Hikaru UENO ${ }^{2}$, \\ Yoshimichi YAMAMOTO ${ }^{3}$ and Hikaru SUZUKI ${ }^{1}$ \\ ${ }^{1}$ Department of Physiology, Nagoya City University Medical School, Mizuho-ku, Nagoya \\ 467-8601, Japan \\ ${ }^{2}$ Department of Biochemistry and Molecular Pathophysiology, Faculty of Medicine, \\ University of Occupational and Environmental Health, Kitakyushu 807-8555, Japan \\ ${ }^{3}$ Department of Physiology, Nagoya City University School of Nursing, Mizuho-ku, \\ Nagoya 467-8601, Japan
}

Received November 5, 2007; Accepted November 15, 2007

\begin{abstract}
The properties of smooth muscle cell hyperpolarization produced by acetylcholine $(\mathrm{ACh})$ were investigated in mesenteric arteries isolated from mice. The resting membrane potential of the smooth muscle cells was about $-60 \mathrm{mV}$. When ACh $(10 \mu \mathrm{M})$ was applied for $1 \mathrm{~min}$, the membrane hyperpolarized with a peak amplitude of about 5 $\mathrm{mV}$ which was reached in about $1 \mathrm{~min}$, following which the potential slowly reverted to the resting level over about 7 min following withdrawal of $\mathrm{ACh}$ from the superfusate (recovery component). Exposure of the artery to $0.5 \mathrm{mM} \mathrm{Ba}^{2+}$, an inhibitor of inward rectifier K-channels, depolarized the membrane by about $13 \mathrm{mV}$, increased the amplitude of the ACh-induced hyperpolarization to about $10 \mathrm{mV}$, and facilitated the visualization of the recovery component. Indomethacine $(10 \mu \mathrm{M})$, an inhibitor of cyclooxygenase, inhibited the recovery component and as a consequence reduced the duration of the hyperpolarization. The ACh-induced response was not markedly altered by either $\mathrm{N}^{\omega_{-}}$ nitro-L-arginine $(10 \mu \mathrm{M})$, an inhibitor of nitric oxide (NO) production, or catalase (130 U/ $\mathrm{ml}$ ), a super oxide scavenger. Exogenously applied hydrogen peroxide $\left(\mathrm{H}_{2} \mathrm{O}_{2}, 300 \mu \mathrm{M}\right)$ hyperpolarized the membrane by about $5 \mathrm{mV}$, which was abolished by catalase. These results suggest that in the mouse mesenteric artery, the ACh-induced hyperpolarization has two components, both an indomethacin-sensitive and an indomethacin-insensitive component. The former component may be produced by prostanoids, while the latter may be produced by factors other than $\mathrm{NO}$ or $\mathrm{H}_{2} \mathrm{O}_{2}$. The results also suggested that the inward rectifier K-channels may be important for producing the resting membrane potential, but they may not be the main contributor to the ACh-induced hyperpolarization of smooth muscle cell membranes in the mouse mesenteric artery.
\end{abstract}

Key words: EDHF, hyperpolarization, prostanoids, $\mathrm{H}_{2} \mathrm{O}_{2}$, inward rectifier K-channel

Correspondence to: Hikaru Suzuki, Ph.D., Department of Physiology, Nagoya City University Medical School, Mizuho-ku, Nagoya 467-8601, Japan Phone: +81-52-853-8129 Fax: +81-52-842-1538 e-mail: hisuzuki@med.nagoya-cu.ac.jp 


\section{Introduction}

ACh hyperpolarizes smooth muscle cell membranes of the mesenteric artery in the rabbit (Kuriyama and Suzuki, 1978; Bolton et al., 1984), guinea-pig (Takata, 1980), rat (Fujii et al., 1992; Fukao et al., 1995) and mouse (Matoba et al., 2000). The hyperpolarization is produced in an endothelium-dependent manner, and the putative mediator has been considered to be endothelium-derived hyperpolarizing factor (EDHF; Chen et al., 1988; Suzuki and Chen, 1990). However, the factor contributing to the generation of the hyperpolarization is equivocal, with possible candidates being EDRF (Bolton et al., 1984; Feletou and Vahoutte, 1988), arachidonic acid metabolites such as the epoxyeicosatrienoic acids (EETs) produced through activation of the enzyme P-450 epoxygenase (Hecker et al., 1994), potassium ions derived from endothelial cells (Edwards et al., 1998) or hydrogen peroxide $\left(\mathrm{H}_{2} \mathrm{O}_{2}\right)$ produced from super oxide anions (Matoba et al., 2000). In the mesenteric artery of the guinea-pig, simultaneous recording of membrane potentials from both endothelial and smooth muscle cells revealed a synchronized hyperpolarization in response to $\mathrm{ACh}$. The response in smooth muscle cells, but not in endothelial cells, was inhibited by the blockade of myo-endothelial gap junctional connections (Yamamoto et al., 1999), thereby suggested that the hyperpolarization of smooth muscle cells may be produced by a passive propagation of the endothelial hyperpolarization to smooth muscle cells through gap junctions (Yamamoto et al., 1998; Yamamoto et al., 1999).

EDHF hyperpolarizes the membrane by increasing the K-conductance, since the amplitude of hyperpolarization is reversely related to the concentration of $\mathrm{K}^{+}$in the superfusate (Chen $e t$ $a l ., 1988$; Chen and Suzuki, 1989), and ACh increases the efflux of incorporated $\mathrm{K}^{+}$in an endothelium-dependent manner (Chen et al., 1988). Attempts have been made to specify the species of K-channels involved in the EDHF response, however the results are controversial. A possible involvement of Ca-sensitive K-channels in the EDHF-induced hyperpolarization is suggested in the rat aorta (Popp et al., 1996). The ACh-induced hyperpolarization is selectively inhibited by apamin in the rabbit mesenteric artery (Murphy and Brayden, 1995), while it is inhibited by charybdotoxin in the rat aorta (Marchenko and Sage, 1996). In some arteries such as the submucosal arterioles in the guinea-pig small intestine (Hashitani and Suzuki, 1997), and both the guinea-pig coronary artery (Nishiyama et al., 1997) and carotid artery (Corriu et al., 1996), the ACh-induced hyperpolarization of the smooth muscle cell membrane is inhibited by co-application of charybdotoxin and apamin, thereby suggesting a contribution of Ca-sensitive Kchannels with intermediate and small conductance. A contribution by inward rectifier Kchannels in the ACh-induced hyperpolarization is also suggested in the rat mesenteric artery (Edwards et al., 1998). The EDHF-response is not inhibited by glibenclamide in the guinea-pig (Chen et al., 1992), rat (Fujii et al., 1992) and rabbit (Murphy and Brayden, 1995; Marchenko and Sage, 1996; Nishiyama et al., 1998; Hattori et al., 2005), thereby suggesting that ATPsensitive K-channels are not involved in the hyperpolarization.

Experiments were carried out to investigate the properties of ACh-induced hyperpolarization in the mouse mesenteric artery. The results would indicate that the AChinduced hyperpolarization has two components, both an indomethacin-sensitive and an indomethacin-insensitive component, with the latter component not inhibited by catalase or L- 
NA. The results do not support the idea that the ACh-induced hyperpolarization is mediated by $\mathrm{H}_{2} \mathrm{O}_{2}$ in the mouse mesenteric artery.

\section{Materials and methods}

Male and female mice (C57BL/6J, 6-8 weeks old) were used. All mice were treated ethically according to the Guidelines for the Use of Experimental Animals, approved by the Animal Treatment Committee of Nagoya City University Medical School.

After anesthesia with fluoromethyl 2,2,2-trifluoro-1-(trifluoromethyl) ethyl ether (sevoflurane, Maruishi Pharm., Osaka, Japan), animals were exsanguinated by decapitation. The proximal parts of the mesenteric artery supplying the ileum were dissected, and cleaned of fatty tissue surrounding the artery. The isolated segment of the artery was immobilized by using tiny pins on the rubber plate fixed at the bottom of the recording chamber $(8 \mathrm{~mm}$ wide $\times$ $30 \mathrm{~mm}$ long $\times 2 \mathrm{~mm}$ deep, with a volume of about $0.5 \mathrm{ml})$, and superfused with warmed $\left(36^{\circ} \mathrm{C}\right)$ Krebs solution, at a constant flow rate of $2 \mathrm{ml} \mathrm{min}^{-1}$ using a peristaltic pump (SMP-23, EYELA, Tokyo Rikakikai Co. Ltd., Tokyo, Japan).

Membrane potentials were recorded from smooth muscle cells using glass capillary microelectrodes (capillary outer diameter, $1.5 \mathrm{~mm}$, inner diameter $0.8 \mathrm{~mm}$, with a fine filament inside; Hilgenberg, Germany) filled with $0.5 \mathrm{M} \mathrm{KCl}$ (the tip resistance ranged between 80 and $150 \mathrm{M} \Omega$ ). Electrical responses recorded with a high input impedance amplifier (Axoclamp-2B, Axon Instruments, Inc., Foster City, California, U.S.A.) were displayed on a cathode-ray oscilloscope (SS-7602, Iwatsu, Osaka, Japan) and were also stored on a personal computer for later analysis.

The ionic composition of the Krebs solution was as follows (mM): $\mathrm{Na}^{+} 137.4, \mathrm{~K}^{+} 5.9, \mathrm{Ca}^{2+} 2.5$, $\mathrm{Mg}^{2+} 1.2, \mathrm{HCO}_{3}{ }^{-} 15.5, \mathrm{H}_{2} \mathrm{PO}_{4}^{-} 1.2, \mathrm{Cl}^{-} 134$, and glucose 11.5 . The high $\left[\mathrm{K}^{+}\right]_{0}$ solution $(13.8 \mathrm{mM})$ was prepared by changing the ratio of $\mathrm{KCl}$ with $\mathrm{NaCl}$. These solutions were aerated with $\mathrm{O}_{2}$ containing $5 \% \mathrm{CO}_{2}$, and the $\mathrm{pH}$ of the solutions was maintained at 7.2-7.3.

Chemicals used were acetylcholine hydrochloride (ACh), atropine sulphate, catalase, indomethacin, hydrogen peroxide $\left(\mathrm{H}_{2} \mathrm{O}_{2}, 31 \%\right.$ solution) and $\mathrm{N}^{\omega}$-nitro-L-arginine (L-NA), all supplied from Sigma Chem., MO (USA). Indomethacin was dissolved first in a small amount (about $2 \mathrm{ml}$ ) of $0.1 \mathrm{M} \mathrm{Na}_{2} \mathrm{CO}_{3}$ solution, and then made up to the final volume with distilled water as a $100 \mathrm{mM}$ solution. All other chemicals were dissolved with distilled water and kept as a stock solution. These solutions were further diluted with Krebs solution, with the ratio more than $1: 1000$. The dilution of chemicals did not alter the $\mathrm{pH}$ of the Krebs solution.

Experimental values were expressed as the mean value \pm standard deviation (S.D.). Statistic significance was tested using the Student's $t$-test, and probabilities of less than $5 \%$ $(P<0.05)$ were considered to be significant.

\section{Results}

\section{Acetylcholine-induced hyperpolarization}

At rest, the cell membranes of the smooth muscle cells of the mesenteric artery of mice 


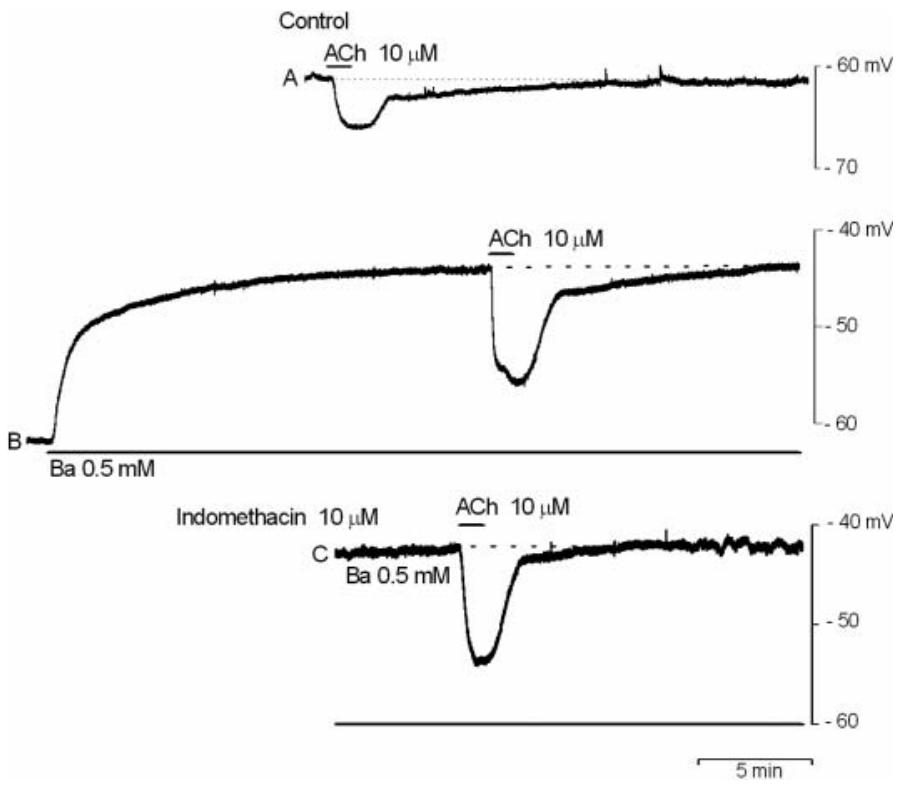

Fig. 1. ACh-induced hyperpolarizations were recorded from smooth muscle cells of the mouse mesenteric artery, in the absence (A) and presence of $0.5 \mathrm{mM} \mathrm{Ba}{ }^{2+}(\mathrm{B})$, and with co-application of both $\mathrm{Ba}^{2+}$ and $10 \mu \mathrm{M}$ indomethacin (C). All responses were recorded from the same tissue preparation. $\mathrm{B}$ and $\mathrm{C}$ are continuous recordings with an approximately $20 \mathrm{~min}$ interruption. Dotted lines in the trace indicate the level of the membrane potential before the application of ACh.

were quiescent, with a stable resting membrane potential ranging between -58 and $-70 \mathrm{mV}$ (mean, $-59.9 \pm 3.0 \mathrm{mV}, \mathrm{n}=13$ ). Application of acetylcholine (ACh, $10 \mu \mathrm{M}$ ) for $1 \mathrm{~min}$ hyperpolarized the membrane, and the potential reverted to the resting level slowly after withdrawal of ACh (recovery component) (Fig. 1A). The hyperpolarization reached the peak amplitude of 3-10 $\mathrm{mV}$ (mean, $5 \pm 1 \mathrm{mV}, \mathrm{n}=7$ ), at 0.6-1.4 min (mean, $0.97 \pm 0.3 \mathrm{~min}, \mathrm{n}=7$ ) after starting the ACh-stimulation. The recovery component ranged between 5 and 10 min (mean, 6.7 $\pm 2.5 \min , \mathrm{n}=7$ ).

Experiments were carried out to observe the ACh-response in the presence of $\mathrm{Ba}^{2+}$, a known inhibitor of inward rectifier K-channels (Hirst and van Helden, 1982). In the presence of $0.5 \mathrm{mM}$ $\mathrm{Ba}^{2+}$, the membrane was depolarized to $-40--51 \mathrm{mV}$ (mean, $-46.4 \pm 3.9 \mathrm{mV}, \mathrm{n}=6 ; P<0.05$ ), and the amplitude of the ACh-induced hyperpolarization was doubled (Fig. 1B). These results indicate that the inward rectifier K-channels may be one of the important factors in the establishment of the resting membrane potential, but they may not be involved in the AChinduced hyperpolarization observed in the mouse mesenteric artery, as was the case in both the guinea-pig mesenteric artery (Hashitani and Suzuki, 1997) and coronary artery (Nishiyama et al., 1998).

\section{Factors involved in the ACh-induced hyperpolarization}

The effects of indomethacin on the ACh-response were examined in the presence of $0.5 \mathrm{mM}$ 

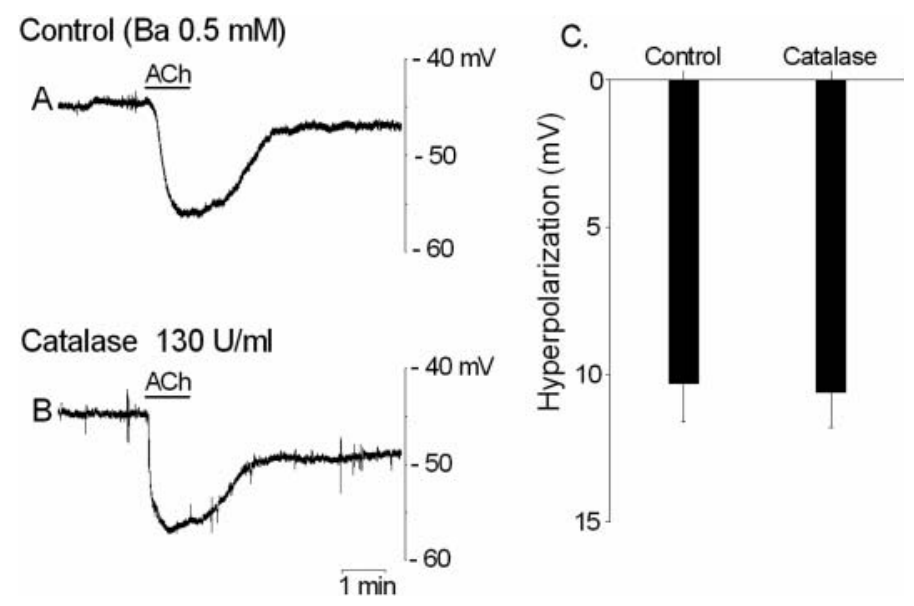

Fig. 2. Effects of catalase on the ACh-induced hyperpolarization of smooth muscle cell membranes in the mouse mesenteric artery. In the presence of $0.5 \mathrm{mM} \mathrm{Ba}{ }^{2+}, \mathrm{ACh}(10$ $\mu \mathrm{M})$ was applied for $1 \mathrm{~min}$, in the absence (A) and presence of $130 \mathrm{U} / \mathrm{ml}$ catalase (B). C, Mean value (+ S.D.) of the peak amplitude of ACh-induced hyperpolarization $(n=4$ for both). No significant difference was observed between the two $(P>0.1)$.

$\mathrm{Ba}^{2+}$, with the result that two components of the ACh-induced hyperpolarization became evident (Fig. 1B). With co-application of indomethacin $(10 \mu \mathrm{M})$ and $\mathrm{Ba}^{2+}$, the average recovery component of the ACh-induced hyperpolarizations was markedly reduced (control, $2.3 \pm 0.4 \mathrm{mV}$; with indomethacin, $0.9 \pm 0.4 \mathrm{mV}, \mathrm{n}=4 ; P<0.05)$, with no significant change in either the average membrane potential (in $\mathrm{Ba}^{2+},-41.5 \pm 2.5 \mathrm{mV}$; with $\mathrm{Ba}^{2+}$ and indomethacin, $-41.2 \pm 2.7 \mathrm{mV} ; \mathrm{n}=4$, $P>0.05$ ) or the average peak amplitude of the ACh-induced hyperpolarizations (control, $12.6 \pm$ $3.2 \mathrm{mV}$; with indomethacin, $11.7 \pm 3.2 \mathrm{mV} ; \mathrm{n}=4 ; P>0.05$ ) (Fig. 1C). As a consequence, the average duration of the ACh-induced hyperpolarizations (12.6 $\pm 3.6 \mathrm{~min}, \mathrm{n}=4)$ was significantly reduced to $3.6 \pm 1.0 \mathrm{~min}(\mathrm{n}=4)$. These results appear to indicate that the recovery component of the ACh-response is produced by prostanoids.

The effects of catalase on ACh-induced hyperpolarization were tested to examine the possible involvement of $\mathrm{H}_{2} \mathrm{O}_{2}$ in the response. High concentrations of catalase $(>300 \mathrm{U} / \mathrm{ml})$ did not allow continuous recording of the membrane potential from the same cell, due to the high viscosity of the solution, and therefore experiments were carried out in solutions containing 130 $\mathrm{U} / \mathrm{ml}$ catalase. This concentration of catalase did not alter either the resting membrane potential (control, $-58.3 \pm 2.0 \mathrm{mV}$; with catalase, $-58.6 \pm 1.5 \mathrm{mV} ; \mathrm{n}=10 ; P>0.1$ ) or the amplitude of the hyperpolarization produced by ACh (control, $5.3 \pm 1.2 \mathrm{mV}$; with catalase, $5.0 \pm 1.9 \mathrm{mV} ; \mathrm{n}=5$; $P>0.1$ ). The effects of catalase were also observed in the presence of $\mathrm{Ba}^{2+}$, so as to facilitate the visualization of the altered hyperpolarizing response, if any, of catalase. As shown in Fig. 2, catalase caused no significant change in the ACh-induced response.

Attempts were made to evaluate the effects of $130 \mathrm{U} / \mathrm{ml}$ catalase on membrane responses produced by $\mathrm{H}_{2} \mathrm{O}_{2}$ in the mouse mesenteric artery. Application of $\mathrm{H}_{2} \mathrm{O}_{2}(300 \mu \mathrm{M})$ hyperpolarized the membrane; the response was very slow in time course, requiring 1.7-3.3 $\min (2.7 \pm 0.6 \mathrm{~min}$, $\mathrm{n}=7)$ to reach the peak amplitude of $4.9 \pm 1.9 \mathrm{mV}(\mathrm{n}=7)$ and the entire duration of 

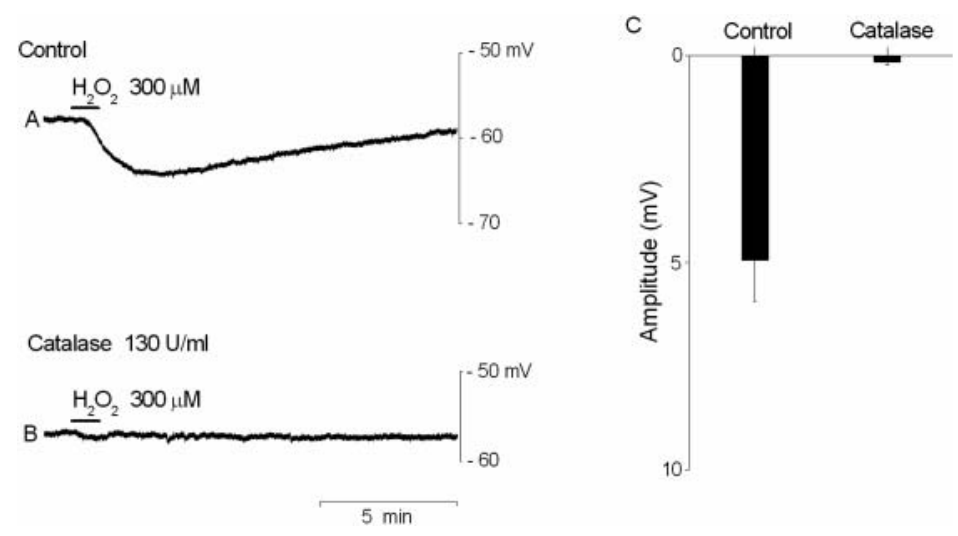

Fig. 3. Effects of catalase on $\mathrm{H}_{2} \mathrm{O}_{2}$-induced hyperpolarization of smooth muscle membranes in the mouse mesenteric artery. $\mathrm{H}_{2} \mathrm{O}_{2}(300 \mu \mathrm{M})$ was applied for $1 \mathrm{~min}$, in the absence (A) and presence of $130 \mathrm{U} / \mathrm{ml}$ catalase (B). A and B were recorded from the same cell. B was recorded 10 min after application of catalase. C, Peak amplitude of $\mathrm{H}_{2} \mathrm{O}_{2-}$ induced hyperpolarization (mean + S.D., $n=7$ ).

hyperpolarization ranged from $6.6 \mathrm{~min}$ to $14.7 \mathrm{~min}(10.8 \pm 3.6 \mathrm{~min}, \mathrm{n}=7)$, in response to $1 \mathrm{~min}$ stimulation with $\mathrm{H}_{2} \mathrm{O}_{2}$ (Fig. 3A). The membrane response was reversible, and required $>15 \mathrm{~min}$ to generate a reproducible amplitude of hyperpolarization with a second $\mathrm{H}_{2} \mathrm{O}_{2}$ application (data not shown). In the presence of catalase, no response was elicited by $\mathrm{H}_{2} \mathrm{O}_{2}$ in the smooth muscle cells of the mouse mesenteric artery (Fig. 3B). The inhibitory effects of catalase on $\mathrm{H}_{2} \mathrm{O}_{2}$ induced hyperpolarization were reversible, and the recovery required over 15 min following the removal of catalase from the superfusate (data not shown). These results suggest that $\mathrm{H}_{2} \mathrm{O}_{2}$ is not involved in ACh-induced hyperpolarization of smooth muscle cells in the mouse mesenteric artery.

The effects of L-NA on ACh-induced hyperpolarization were examined in smooth muscle cells of the mouse mesenteric artery. L-NA $(10 \mu \mathrm{M})$ did not alter either the resting membrane potential $(-58.6 \pm 1.9 \mathrm{mV}$; in L-NA, $-59.3 \pm 1.5 \mathrm{mV}$; $\mathrm{n}=12$; $P>0.05)$ or the peak amplitude of AChinduced hyperpolarization (control, $4.4 \pm 1.1 \mathrm{mV}$; in L-NA, $4.2 \pm 1.1 \mathrm{mV} ; \mathrm{n}=12 ; P>0.05$ ). These results would appear to indicate that NO is not involved in the ACh-induced hyperpolarization in the mouse mesenteric artery.

\section{Discussion}

The present experiments revealed that in the mouse mesenteric artery, the ACh-induced hyperpolarization of the smooth muscle cell membrane is formed from two components, one which is indomethacin-sensitive and the other which is indomethacin-insensitive. The former component appeared as the recovery component following removal of ACh from the superfusate. This component may be produced by prostanoids, possibly prostacyclin, as is the case in both the guinea-pig coronary artery (Parkington et al., 1993; Nishiyama et al., 1998; Yajima et al., 1998) and the rabbit mesenteric artery (Murphy and Brayden, 1995). A slow rate 
of action may be one of the characteristics of prostanoids, as this has been observed in the electrical and mechanical responses to prostanoids in different arteries (Parkington et al., 1993; Murphy and Brayden, 1995; Zhang et al., 1996; Nishiyama et al., 1998; Yajima et al., 1998). In the mouse mesenteric artery, the recovery component was not always clear in the resting condition, but it could be clearly seen after inhibiting the inward rectifier K-channels with $\mathrm{Ba}^{2+}$, possibly due to depolarization of the membrane. The indomethacin-insensitive component of the ACh-induced hyperpolarization was not inhibited by nitroarginine, suggesting that this potential was produced by factors other than prostanoids and NO.

In the mouse mesenteric artery, the ACh-induced hyperpolarization is reportedly produced by endothelial $\mathrm{H}_{2} \mathrm{O}_{2}$, as it can be inhibited by catalase (Matoba et al., 2000). However, the present experiments did not detect a contribution of $\mathrm{H}_{2} \mathrm{O}_{2}$ to the hyperpolarization response. An important reason for this failure might be related to the difference in concentration of catalase; the concentration of catalase used by Matoba et al. (2000) (equal to 1,250 U/ml) was not applicable to our experimental system, due to the high viscosity of the solution. The concentration of catalase tested in the present experiments (equal to $130 \mathrm{U} / \mathrm{ml}$ ) was nearly maximal in allowing successful continuous recording of cell membrane activity from the same smooth muscle cell. Inhibition of the ACh-induced relaxation by catalase was also observed in the mouse aorta, but the concentrations used ranged from 800 to 2,400 U/ml (Rabelo et al., 2003), which was again far beyond a concentration that could be used in our system for these electrophysiological experiments. The significant inhibition of endothelium-dependent relaxation by high concentrations of catalase in wild mice but not in LDL receptor mutant mice (Fig. 2 in Rabelo et al., 2003) suggests that these concentrations of catalase inhibit endothelial functions including the production of NO. The present experiments showed that in the mouse mesenteric artery, catalase at a concentration of $130 \mathrm{U} / \mathrm{ml}$ abolished the hyperpolarization response produced by $\mathrm{H}_{2} \mathrm{O}_{2}$, with no significant effect on the ACh-induced hyperpolarization. Thus, it seems likely that the ACh-induced hyperpolarization is not produced by $\mathrm{H}_{2} \mathrm{O}_{2}$. This was also suggested by the difference between $\mathrm{H}_{2} \mathrm{O}_{2}$ and $\mathrm{ACh}$ in the time course of the membrane potential changes; the hyperpolarization produced by ACh reached peak amplitude about 1 min after its application, while with $\mathrm{H}_{2} \mathrm{O}_{2}$-induced hyperpolarization, peak amplitude was reached in about $5 \mathrm{~min}$. Similar differences were also found in the recovery process from the hyperpolarization. Thus, no supportive evidence for the contribution of $\mathrm{H}_{2} \mathrm{O}_{2}$ in the AChinduced hyperpolarization was obtained in these experiments with the mouse mesenteric artery.

In the guinea-pig mesenteric artery, the ACh-induced hyperpolarization of the smooth muscle cell membrane is inhibited by calibdotoxin and apamin (Hashitani and Suzuki, 1997). Significant inhibition of the ACh-induced hyperpolarization by calibdotoxin is also observed in both guinea-pig coronary (Nishiyama et al., 1998) and mesenteric arterioles (Yamamoto et al., 1999). These observations strongly suggest that the hyperpolarization is produced by activation of intermediate conductance K-channels with some contribution of small conductance Kchannels. However in the rat mesenteric artery, a possible involvement of inward rectifier Kchannels in the ACh-induced hyperpolarization is suggested (Edwards et al., 1998). This was also tested in the mouse mesenteric artery, by using $\mathrm{Ba}^{2+}$, an inhibitor of inward-rectifier $\mathrm{K}$ channels. Application of $\mathrm{Ba}^{2+}$ significantly depolarized the membrane, suggesting that inward 
rectifier K-conductance was important in the production of the resting membrane potential, as had been previously shown in the guinea-pig mesenteric artery (Hirst and van Helden, 1982; Hashitani and Suzuki, 1997). As ACh hyperpolarized the membrane in the presence of $\mathrm{Ba}^{2+}$, the contribution of inward rectifier K-channels in production of the response in the mouse mesenteric artery may be very small, if at all, unlike the case in the rat mesenteric artery (Edwards et al., 1998).

In the rabbit mesenteric artery, the hyperpolarization produced by $\mathrm{H}_{2} \mathrm{O}_{2}$ is inhibited by glibenclamide, thereby suggesting an involvement of ATP-sensitive K-channels (Hattori et al., 2003). Although the present experiments did not test the effects of glybenclamide on AChinduced hyperpolarization in the mouse mesenteric artery, no contribution of ATP-sensitive Kchannels in the EDHF response have been observed in many types of artery (Parkington $e$ al., 1993; Fukao et al., 1995; Murphy and Brayden, 1995; Nishiyama et al., 1998). These results again weaken the possibility that the ACh-induced hyperpolarization is produced by $\mathrm{H}_{2} \mathrm{O}_{2}$ in the mouse mesenteric artery.

It is concluded that in the mouse mesenteric artery, ACh hyperpolarized the smooth muscle cell membrane with two components, one which is indomethacin-sensitive and the other which is indomethacin-insensitive. The former forms the recovery component, and may be produced by prostanoids, while the latter may be produced by factors other than $\mathrm{H}_{2} \mathrm{O}_{2}$ or NO. The inward rectifier K-channels may have an important role in the maintenance of the resting membrane potential, but not in the ACh-induced hyperpolarization in smooth muscle cells of the mouse mesenteric artery.

\section{References}

Bolton, T.B., Large, R.F. and Takewaki, T. (1984). Mechanism of action of noradrenaline and carbachol on smooth muscle of guinea-pig anterior mesenteric artery. J. Physiol. (Lond) 351: 549-572.

Chen, G. and Suzuki, H. (1989). Some electrical properties of the endothelium-dependent hyperpolarization recorded from rat arterial smooth muscle cells. J. Physiol. (Lond.) 410: 91106.

Chen, G., Suzuki, H. and Weston, A.H. (1988). Acetylcholine releases endothelium-derived hyperpolarizing factor and EDRF from rat blood vessels. Br. J. Pharmacol. 95: 1165-1174.

Corriu, C., Félétou, M., Canet, E. and Vanhoutte, P.M. (1996). Endothelium-derived factors and hyperpolarizations of the isolated carotid artery of the guinea-pig. Br. J. Pharmacol. 119: 959964.

Edwards, G., Dora, K.A., Gardener, M.J., Garland, C.J. and Weston, A.H. (1998). K+ is an endotheliumderived hyperpolarizing factor in rat arteries. Nature 396: 702-709.

Feletou, M. and Vanhoutte, P.M. (1988). Endothelium-dependent hyperpolarization of canine coronary artery smooth muscle. Br. J. Pharmacol. 93: 515-524.

Fujii, K., Tominaga, M., Ohmori, S., Kobayashi, K., Koga, T., Takata, Y. and Fujishima, M. (1992). Decreased endothelium-dependent hyperpolarization to acetylcholine in smooth muscle of the mesenteric artery of spontaneously hypertensive rats. Circ. Res. 70: 660-669.

Fukao, M., Hattori, Y., Kanno, M., Sakuma, I. and Kitabatake, A. (1995). Evidence for selective inhibition by lysophosphatidylcholine of acetylcholine-induced endothelium-dependent hyperpolarization and relaxation in rat mesenteric artery. Br. J. Pharmacol. 116: 1541-1544.

Hashitani, H. and Suzuki, H. (1997). $\mathrm{K}^{+}$channels which contribute to the acetylcholine-induced 
hyperpolarization in smooth muscle of the guinea-pig submucosal arteriole. J. Physiol. (Lond.) 501: 319-329.

Hattori, T., Kajikuri, J., Katsuya, H. and Itoh, T. (2003). Effects of $\mathrm{H}_{2} \mathrm{O}_{2}$ on membrane potential of smooth muscle cells in rabbit mesenteric resistance artery. Eur. J. Pharmacol. 464: 101-109.

Hirst, G.D.S. and van Helden, D.F. (1982). Ionic basis of the resting potential of submucosal arteries in the ileum of the guinea-pig. J. Physiol. (Lond.) 333: 53-67.

Hecker, M., Bara, A.T., Bauersachs, J. and Busse, R. (1994). Characterization of endothelium-derived hyperpolarizing factor as a cytochrome P450-derived arachidonic acid metabolite in mammals. J. Physiol. (Lond.) 481: 407-414.

Kuriyama, H. and Suzuki, H. (1978). The effects of acetylcholine on the membrane and contractile properties of smooth muscle cells of the rabbit superior mesenteric artery. Br. J. Pharmacol. 64: 493-501.

Marchenko, S.M. and Sage, S.O. (1996). Calcium-activated potassium channels in vascular endothelium of intact rat aorta. J. Physiol. (Lond.) 492: 53-60.

Matoba, T., Shimokawa, H., Nakashima, M., Hirakawa, Y., Mukai, Y., Hirano, K., Kanaide, H. and Takeshita, A. (2000). Hydrogen peroxide is an endothelium-derived hyperpolarizing factor in mice. J. Clin. Invest. 106: 1521-1530.

Murphy, M.F. and Brayden, J.E. (1995). Apamin-sensitive $\mathrm{K}^{+}$channels mediate an endotheliumdependent hyperpolarization in rabbit mesenteric artery. J. Physiol. (Lond.) 489: 723-734.

Nishiyama, M., Hashitani, H., Fukuta, H., Yamamoto, Y. and Suzuki, H. (1998). Potassium channels activated in the endothelium-dependent hyperpolarization in guinea-pig coronary artery. $J$. Physiol. (Lond.) 510: 455-465.

Parkington, H.C., Tara, M.A., Tonta, M.A. and Coleman, H.A. (1993). Stretch revealed three components in the hyperpolarization of guinea-pig coronary artery in response to acetylcholine. J. Physiol. (Lond.) 484: 469-480.

Popp, R., Bauersachs, J., Hecker, M., Fleminf, I. and Busse, R. (1996). A transferable $\beta$-naphtoflavoneinducible, hyperpolarizing factor is synthesized by native and cultured porcine endothelial cells. J. Physiol. (Lond.) 497: 699-709.

Rabelo, L.A., Cortes, S.F., Alvarez-Leite, J.I. and Lemos, V.S. (2003). Endothelium dysfunction in LDL knockout mice: a role for $\mathrm{H}_{2} \mathrm{O}_{2}$. Br. J. Pharmacol. 138: 1215-1220.

Suzuki, H. and Chen, G. (1990). Endothelium-derived hyperpolarizing factor (EDHF): an endogenous potassium-channel activator. News in Physiol. Sci. 5: 212-215.

Takata, Y. (1980). Regional differences in electrical and mechanical properties of guinea-pig mesenteric vessels. Jpn. J. Physiol. 30: 709-728.

Yamamoto, Y., Fukuta, H., Nakahira, Y. and Suzuki, H. (1998). Blockade by $18 \beta$-glycyrrhetinic acid of intercellular electrical coupling in guinea-pig arterioles. J. Physiol. (Lond.) 511: 501-508.

Yamamoto, Y., Imaeda, K. and Suzuki, H. (1999). Endothelium-dependent hyperpolarization and intercellular electrical coupling in guinea-pig mesenteric arterioles. J. Physiol. (Lond.) 514: 505513.

Yamamoto, Y., Klemm, M.F., Edwards, F.R. and Suzuki, H. (2001). Intercellular electrical communication among smooth muscle and endothelial cells in guinea-pig mesenteric arterioles. J. Physiol. (Lond.) 535: 181-195.

Yajima, K., Nishiyama, M., Yamamoto, Y. and Suzuki, H. (1999). Inhibition of endothelium-dependent hyperpolarization by endothelial prostanoids in guinea-pig coronary artery. Br. J. Pharmacol. 126: $1-10$.

Zhang, G., Niwa, H., Masaoka, A., Yamamoto, Y. and Suzuki, H. (1996). Endothelial prostanoids involved in the relaxation produced by acetylcholine in the human pulmonary artery. Jpn. J. Physiol. 46: 403-409. 